\title{
Health Care Reinsurance and Insurance Reform in the United States: A Simulation Model
}

\author{
David Bernstein* \\ Office of Economic Policy, U.S. Treasury, 8204 Franklin Drive, Lorton, VA 22079, U.S.A. \\ E-mail: spstat@yahoo.com
}

This paper uses data from the Medical Expenditures Panel Survey, a U.S. health care survey, to simulate the impact of reinsurance on insured health care expenditures for different cohorts. The paper concludes that reinsurance would not eliminate potential risk selection by insurers and, even with reinsurance, specific cohorts would have trouble obtaining affordable insurance unless reinsurance was accompanied by significant changes to U.S. insurance laws including the adoption of guarantee issue requirements and the abolition of underwriting based on health status or pre-existing conditions. The simulation model reveals that the impact of reinsurance on insurance expenditures is larger for older cohorts than for younger cohorts.

The Geneva Papers (2010) 35, 568-580. doi:10.1057/gpp.2010.19

Keywords: health insurance; coverage; reinsurance

\section{Background}

Some economists including Swartz ${ }^{1}$ and Blumberg and Holahan ${ }^{2}$ have examined the use of reinsurance as a means to expand health coverage to the uninsured. The literature has focused on two direct benefits attributable to a reinsurance programme. First, reinsurance programmes reduce insurance plan risk and lower risk leads to reduced premiums. Second, a publicly subsidised reinsurance programme is a subsidy, which is shared between the insurance company and its customers.

The impact of reinsurance will differ across cohorts or groups defined by age and health status. However, even with reinsurance the availability and the price charged for insurance will still hinge on how insurance markets are regulated. Even with reinsurance, younger relatively healthy applicants may find insurance to be unaffordable if they reside in a community-rating State, where all insurance applicants are charged the same premium for insurance regardless of their age or health status. In contrast, even with reinsurance, older or unhealthy adults may be denied insurance altogether or may find health insurance unaffordable if they live in a state without significant restrictions on the underwriting of health insurance policies. Reinsurance

\footnotetext{
* The author is employed as an economist in the Office of Economic Policy of the U.S. Treasury. The views expressed here belong exclusively to the author and do not represent a position of the Office of Economic Policy or the U.S. Treasury.

${ }^{1}$ Swartz (2003).

${ }^{2}$ Blumberg and Holahan (2004).
} 
will reduce, but will not eliminate, the incentive for insurance companies to adopt selection methods.

The previous literature has not measured differences in the cost of reinsurance across cohorts or groups and how these differences might affect the perception of the insurance industry on the costs and benefits of different regulatory regimes. This paper uses survey data, the Medical Expenditures Panel Survey (MEPS), on U.S. health care expenditures and a simple simulation model of insurance paid expenditures to assess the impact of reinsurance programmes on different cohorts. The analysis presented here suggests that a reinsurance subsidy could facilitate the adoption of regulations restricting or eliminating the underwriting health insurance policies based on the health status of the applicant.

This paper pertains to health care markets in the United States and results may not be applicable to other markets with different institutions and incentives. The next section of the paper reviews pertinent literature on health insurance markets, regulation of insurance markets in the United States and reinsurance programmes. The subsequent section discusses the data and methodology used to measure the potential impact of reinsurance on health expenditures, which are paid by insurance firms. The penultimate section presents and discusses the simulation results. The discussion of policy implications in the final section includes an assessment of whether a reinsurance programme would effectively complement changes in health insurance regulations currently being proposed in the United States.

\section{Pertinent literature}

An understanding of how reinsurance could facilitate expanded health insurance coverage requires knowledge of health insurance markets and an understanding of the role of reinsurance.

\section{Background on issues impacting health insurance coverage}

The literature on individuals who lack health insurance in the United States stresses two separate age cohorts, younger adults just entering the workforce and older adults prior to leaving the workforce. It has been difficult to provide health insurance to both of these populations albeit for different reasons. Collins et al. ${ }^{3}$ found that the number of uninsured young adults aged 19 to 29 years old rose from 11.2 million in 2000 to 13.7 million in 2004, accounting for over 40 per cent of the recent increase in the uninsured under age 65. Jacobson et al. ${ }^{4}$ found that there were fewer uninsured among the 55-64-year-old age group but older uninsured individuals were in relatively poor health and were more likely to be denied coverage in the individual market.

Most of the focus of the current health care debate in the United States is on how to help older workers with pre-existing conditions; but issues pertaining to younger

\footnotetext{
${ }^{3}$ Collins et al. (2006).

${ }^{4}$ Jacobson et al. (2009).
} 
workers are equally important. Bernstein ${ }^{5}$ estimates that under a prototypical comprehensive health plan, more than 55 per cent of applicants between the age of 23 and 32 make claims under US\$500 during the year. By contrast, around 20 per cent of applicants between the age of 53 and 62 make less than US $\$ 500$ in health care claims. This difference in claim rates could result in many younger households eschewing insurance coverage, especially if they are charged the same rate as older households.

Around 95 per cent of working-age individuals with health insurance obtain health insurance through their employer or through their spouse's employer. Clemens-Cope and Bowen ${ }^{6}$ show that only around 53 per cent of workers in firms with fewer than ten employees have employer-sponsored health insurance, compared to over 85 per cent of employees in firms with more than 100 employees. Moreover, increases in health costs have resulted in a decline of nearly 4 percentage points in the number of workers in firms with ten or fewer employees who are covered by health insurance.

Factors impacting the cost and availability of health insurance, including the relative premiums charged to young versus old applicants, are determined by insurance regulations. Kofman and Politz ${ }^{7}$ and the Center for Affordable Health Insurance ${ }^{8}$ provide a useful discussion of insurance regulation in the United States.

There are three different health insurance markets, the individual health insurance market, the small firm market and the large firm market, each with different regulatory systems. In the United States, health care is regulated by both federal and state governments. In general, most large firm health insurance is regulated by the federal government. Federal health insurance regulations stem from three laws: (1) The Employment Retirement and Security Act (ERISA) (1974); (2) The Health Insurance Portability and Adjustment Act (HIPAA) (1996); and, (3) the Consolidated Omnibus Budget Reconciliation Act (1986). Current federal laws do not require firms to insure their workers. Moreover, ERISA prohibits State regulation of firms that self-insure and the imposition of coverage or payment mandates on employers.

HIPAA requires all insurance firms to extend some offers of insurance to small firms. The federal government does not require insurance firms to offer a health insurance policy to individual applicants in the individual market. States can choose to impose guarantee-issue rules in the individual market. The federal government does not impose restrictions on premiums in any markets and premium regulation for both the individual and small group market is left to the discretion of State governments.

States use three types of rate regulations: (1) rate band; (2) modified community rating; and, (3) pure community rating for both small group and individual markets. Under rate-band regulation, States can use information about health status and other factors (commonly age, group size, family composition, smoking status and possibly

\footnotetext{
${ }^{5}$ Bernstein (2008).

${ }^{6}$ Clemens-Cope and Bowen (2006).

${ }^{7}$ Kofman and Politz (2006).

${ }^{8}$ Center for Affordable Health Insurance (2006).
} 
gender) to set rates. Rate-band regulations do restrict the amount rates can differ based on these various factors, but in many States the amount of permissible variability in regulations is fairly large. A model rate bank devised by the National Association of Insurance Commissioners allowed for a 200 per cent variability in rates because of health status and total premium variability of 26 to one. Under modified community rating, States are not allowed to use information on health status to establish rates. Information on other factors can be used. Pure community rating provides for one premium for all individuals in the State.

The difference in stringency of guarantee-issue and rate regulation between group and non-group market is stark. In non-group markets, only ten States impose a guaranteed issue requirement. Seven States impose some sort of rate regulation in the individual market. The other 43 States do not have formal rate band or community rating. However, rates are subject to review by the State insurance regulator. In the small-group market, all States have some limit on dispersion of rates. Thirty-seven States impose rate-band regulations and 13 States apply some form of community rating or adjusted community rating. However, there is wide variability in the factors that are used to determine insurance premiums charged to firms and in the size of the allowable variability. Data on small-group market regulation reported by Kofman and Pollitz reveals that variability in premiums based on health status typically ranges from +-10 per cent per health status class to +-35 per cent.

The type of state regulation has important ramifications for different age cohorts and different health status groups. In general, younger cohorts and healthy individuals tend to be better off in States with little regulation, where health insurance firms are free to charge lower rates to younger or healthier applicants. Older cohorts and unhealthy individuals are better off in States where insurance firms must offer an insurance policy to all applicants and community rating requires that all applicants receive the same rate.

\section{The role of reinsurance and risk-adjustment}

Health insurance markets are impacted by the problem of adverse selection under which high-risk patients tend to purchase expensive policies and low-risk workers tend to purchase less expensive policies. Newhouse ${ }^{9}$ points out that one way to mitigate the adverse selection problem is through risk adjustment, a process through which funds are transferred from insurers of low-risk patients to insurers of high-risk patients.

A recent proposal by Haislmaier attempts to expand health insurance coverage through risk-adjustment methods. Haislmaier proposes to create a risk-transfer pool, a mechanism which spreads the costs of relatively few individuals with extreme medical conditions evenly over all insurers and policy-holders in the market. Under this system no single insurer is placed at a financial disadvantage if it attracts more extreme cases than its competitors. The funding system proposed by Haislmaier is based on actual health insurance expenditures rather than projected expenditures; thereby, making the

\footnotetext{
${ }^{9}$ Newhouse (1986).
} 
system less complicated. Haislmaier's plan does not include public funding, and does not lower the cost of insurance or reduce the tendency for some individuals to eschew coverage. The risk-transfer pool will reduce, but not eliminate, adverse selection problems caused by sicker individuals gravitating towards more generous health plans. The extent of the reduction in adverse selection depends on the extent to which the risk transfer pool transfers funds among insurers.

Swartz ${ }^{1}$ favours a government-funded reinsurance programme under which the government pays insurers some per cent of costs over a particular threshold. In addition to reducing the risk of insurance and reducing selection incentives, government-funded reinsurance directly reduces insurance company costs because of the government subsidy.

The evidence that publicly funded reinsurance programmes would both reduce health insurance costs and risk in health insurance markets is especially persuasive. A series of papers, Berk and Monheit ${ }^{10}$ and Berk et al. ${ }^{11}$ found a disproportionate share of health care costs are realised by a relatively small number of individuals. In particular, these papers have found that 5 per cent of all individuals are consistently responsible for more than 50 per cent of all health care expenditures.

Results published in Blumberg and Holahan ${ }^{2}$ find that a high-threshold reinsurance programme is a relatively economical way to reduce insurance plan risk. They estimate that a high-threshold reinsurance programme that was limited to the small group and individual market would cost around US $\$ 23$ billion per year. Moreover, these results indicate a reinsurance programme that lowers expenses by less than 10 per cent can reduce the variance of expenditures by 50 per cent or more.

Another possible advantage of reinsurance, noted by Swartz, ${ }^{1}$ is the reduction in resources insurance companies apply to identify high-risk consumers and either exclude them from coverage or charge them higher rates. Cutler and Zeckhauser ${ }^{12}$ point out one way insurance firms impact the risk profile of people who enroll in their health insurance plans is through design of their benefit policy. A firm that wants to discourage enrolment of individuals with certain high-cost groups, diabetics and/or individuals with mental health issues, might simply design a health plan with less generous benefits for these two problems. Reinsurance would only help mitigate this incentive if cost differentials stemming from these health conditions were concentrated among the most expensive health care cases. By contrast, if median insurance costs for individuals with a particular health care condition were substantially higher than median health care costs for individuals without a particular condition, there would be little incentive for insurance firms to forego the use of methods impacting insurance plan selection.

The evidence that reinsurance will reduce incentives for insurance firms to adopt selection incentives is less clear cut than the evidence pertaining to health insurance price and risk. If, even with reinsurance, it proves unprofitable to insure high-risk

\footnotetext{
${ }^{10}$ Berk and Monheit (1992 and 2001).

${ }^{11}$ Berk et al. (1988).

${ }^{12}$ Cutler and Zeckhauser (2000).
} 
individuals, insurance firms may have an incentive to continue spending on efforts to select better risks.

\section{Data and methodology}

Data

The data used in this study are the 1999 to 2006 Medical Expenditures Panel (MEPs) databases, a person-level survey covering a wide range of variables relevant to health expenditures, utilisation, health status and the socio-economic status of the population in the United States. The key data item inputted into the simulation model is total household health care expenditures from all sources, out-of-pocket expenditures, private insurance expenditures and public insurance expenditures.

The analysis is based on individuals and households who currently have some private insurance during the year. Health expenditures are higher for people with insurance than for people without insurance. Since a reinsurance programme expanding insurance coverage would increase health expenditures for people who do not currently have insurance, the cost and expenditure estimates presented here are based on households and individuals who currently have insurance.

Multiple years of data are used because a relatively small number of individuals and households have extremely high health care costs and multiple years are needed to obtain reliable health care cost estimates. All data is inflated to 2006 (in Dollars) on the basis of the medical care CPI index.

A quick look at total health insurance cost data for different age cohorts are presented in Table 1. The statistics reveal that the mean, the median, the proportion of individual with more than US $\$ 50,000$ in health care expenses and the proportion of health expenses over a US\$50,000 limit all increase with age. These results suggest most of the impact of reinsurance occurs because of its impact on the costs of insuring older individuals.

\section{Methodology}

Reinsurance impacts the amount of health care expenses an insurance firm must pay to its customers. In order to estimate the impact of reinsurance on different cohorts,

Table 1 Some statistics on health expenditures across age groups

\begin{tabular}{lccccc}
\hline Person age & $21-35$ & $36-50$ & $51-65$ & $\begin{array}{c}\text { Ratio age } \\
36-50 \text { to } 21-35\end{array}$ & $\begin{array}{c}\text { Ratio age } \\
51-65 \text { to 36-50 }\end{array}$ \\
\hline $\begin{array}{l}\text { Mean health expenditures } \\
\text { Median health expenditures }\end{array}$ & $\$ 2,578$ & $\$ 3,642$ & $\$ 6,671$ & 1.4 & 2.6 \\
$\%$ individuals with health & $0.28 \%$ & $0.59 \%$ & $1.80 \%$ & 2.1 & 3.6 \\
$\begin{array}{l}\text { expenditure }>\text { US\$50,000 } \\
\% \text { health care expenditures } \\
\text { exceeding a US\$50,000 limit }\end{array}$ & $5.1 \%$ & $9.4 \%$ & $13.4 \%$ & 1.8 & 2.6 \\
\hline
\end{tabular}

Source: Tabulations on individual health insurance expenditures from the 1999 to 2006 MEPS inflated to 2006 dollars based on the medical care health price index. 
we estimate insurance expenditures for a typical health plan both with and without the reinsurance. The estimation procedure was used and originally described by Bernstein. ${ }^{5}$

The basic simulation model involves a five-step procedure: (1) creation of an individual-level database on health expenditures; (2) creation of a database with information on household health expenditures and information on whether the household was covered by a family or individual plan; (3) parameters of the health insurance plan; (4) the merging of household information with insurance policy information; and, (5) the calculation of insurance company expenditure information.

The inputs for the estimation of the insurance expenditure are MEPS data on total household health expenditures and payment parameters for a typical health plan. The MEPS health expenditure data were increased by 27 per cent to account for a potential undercount in expenditures on the MEPS database. A discussion of the undercount can be found in Selden et al. ${ }^{13}$ and a discussion of the adjustment can be found in Blumberg and Holahan. ${ }^{2}$

Health insurance company expenditures paid from a simple health insurance plan are defined by three parameters - the deductible, the coinsurance rate and the out-ofpocket limit. ${ }^{14}$ Insurance plan parameters differ for single-plan policies (households with one insured person) and family-plan policies (households with more than one insured person.) Typically, coinsurance rates are identical for family plans and singleindividual plans, while deductibles and out-of-pocket limits are higher for the family plan. The out-of-pocket limit, coinsurance rate and deductible for the insurance plans used in this paper are presented in Table 2. The programme can be modified to allow for different insurance plan parameters but results are not sensitive to the assumed parameters.

Insurance company expenditure for each household (both with and without reinsurance) is estimated based on these insurance plan parameters and the MEPS data on household health expenditures. In the basic model without reinsurance, insurance company expenditures are defined by three different household income intervals.

- Insurance expenditures are zero for household health expenditures below the deductible.

- Insurance expenditures are a reimbursement rate multiplied by the difference between household health expenses and the deductible for household health expenditures between the deductible and the threshold where the out-of-pocket limit is reached. ${ }^{15}$

13 Selden et al. (2001).

${ }^{14}$ Expenditure from an actual insurance plan might also be affected by more detailed stipulations in the contract.

${ }^{15}$ The household expenditure limit triggering the maximum allowable out-of-pocket expenditures is given by thres $=$ deduc $+($ moutp - deduc $) /$ coin_rate.

In this equation, thres is the household expenditure level where actual household out-of-pocket expenditure equals the allowable maximum, deduc is the plan deductible, moutp is the maximum allowable out-of-pocket limit, and coin_rate is the per cent of health expenses paid by the household for health expenditures between the deductible and the threshold defined here. Bernstein (2008) provides more detail on this algorithm. 
Table 2 Health plan and reinsurance parameters

\begin{tabular}{lcrr}
\hline & Out-of-pocket limit US\$ & Coinsurance rate (\%) & Deductible \\
\hline Single & US \$4,000 & 20 & US \$1,000 \\
Family & US \$6,000 & 20 & US \$2,000 \\
\hline & Reinsurance rate & Reinsurance limit \\
\hline Potential reinsurance parameters & 0.8 & US $\$ 50,000$ \\
Single & 0.8 & US $\$ 50,000$ \\
Family & & \\
\hline
\end{tabular}

Assumptions on insurance plan parameters used in this paper.

- Insurance expenses are the sum of the out-of-pocket limit and the difference between health expenditures and the expense threshold triggering the maximum allowable out-of-pocket expenses.

When a reinsurance benefit exists some high-end health insurance expenditures are paid by the reinsurance firm. The insurance company pays all health expenditures for health expenditures between the level triggering the maximum allowable out-of-pocket expenditure and the level of health expenditures triggering reinsurance payments. Insurance company expenditures are reduced by the reinsurance payments, once reinsurance payments begin, as stipulated by the parameters of the reinsurance policy. In this paper, the reinsurance policy pays 20 per cent of health expenditures over US $\$ 50,000$.

Separate insurance cost estimates are presented for households insured under a family plan and households insured under a single-individual plan. For family plans, age was defined as the age of the oldest person in the household. The maximum age for the sample used to estimate health insurance expenditures was 62 .

\section{Results}

Table 3 contains estimates of the average health insurance company expenditure for different age cohorts. The data in Table 3 reveals a sharp increase in insurance expenditures across age groups both with and without reinsurance. The ratio of estimated family-plan average insurance expenditures in the 51-65 to 21-35 age groups is 2.9 with no reinsurance and 2.6 with reinsurance. The corresponding single-plan ratios are 5.0 with no reinsurance and 4.5 with reinsurance. Reinsurance provides only a modest change in the incentive for insurance companies to choose younger individuals over older individuals.

Table 3 also contains information on median insurance expenditure across age cohorts. The median insurance company expenditure statistic describes what an insurance company must pay for the "typical" household with typical health and expenditure levels. Median insurance company expenditures are unaffected by the reinsurance since reinsurance only affects insurance payouts for a relatively small number of high-expenditure cases. The data reveals that median insurance 
Table 3 Insurance company costs by plan type and age

\begin{tabular}{|c|c|c|c|}
\hline Age of household head & $\begin{array}{l}\text { Mean costs no } \\
\text { reinsurance (US\$) }\end{array}$ & $\begin{array}{c}\text { Mean costs reinsurance } \\
80 \% \text { over } \$ 50,000(U S \$)\end{array}$ & $\begin{array}{l}\text { Median insurance } \\
\text { costs (US\$) }\end{array}$ \\
\hline \multicolumn{4}{|l|}{ Family plans } \\
\hline $21-35$ & US $\$ 5,350$ & US $\$ 4,808$ & US $\$ 745$ \\
\hline $36-50$ & US $\$ 9,980$ & US $\$ 8,811$ & US $\$ 4,372$ \\
\hline $51-65$ & US $\$ 15,518$ & US \$12,577 & US $\$ 6,930$ \\
\hline All family plans & US $\$ 10,512$ & US $\$ 8,934$ & US $\$ 3,942$ \\
\hline \multicolumn{4}{|l|}{ Single-individual plans } \\
\hline $21-35$ & US $\$ 1,172$ & US $\$ 1,060$ & US $\$ 0$ \\
\hline $36-50$ & US $\$ 2,816$ & US $\$ 2,425$ & US \$0 \\
\hline $51-65$ & US $\$ 5,840$ & US $\$ 4,774$ & US $\$ 1,122$ \\
\hline All single plans & US $\$ 2,603$ & US $\$ 2,212$ & US $\$ 0$ \\
\hline \multicolumn{4}{|l|}{ Entire sample } \\
\hline $21-35$ & US $\$ 4,041$ & 3633.88 & US \$78 \\
\hline $36-50$ & US $\$ 9,099$ & 8024.99 & US $\$ 3,512$ \\
\hline $51-65$ & US $\$ 14,181$ & $11,499.67$ & US $\$ 5,729$ \\
\hline All households & US $\$ 9,006$ & US $\$ 7,653$ & US $\$ 2,570$ \\
\hline
\end{tabular}

Source: Tabulations from MEPS 1999 to 2006 based on insurance expenditure algorithm.

expenditures are US \$0 for single-plan households in the 21-35- and 36-50-year-old age group. Insurance can have a critical impact on health outcomes for sick individuals; however, most individuals (especially young ones) are typically healthy. The low median health care expenditures for younger single cohorts may be one reason why these cohorts have a high uninsured rate.

The data in Table 3 is used to obtain estimates of the gain from reinsurance for different cohorts with results presented in Table 4 . The results reveal (not surprisingly) a larger decrease in insurance expenditures for older cohorts than for younger cohorts. For instance, the decrease in family-plan insurance expenditures stemming from reinsurance is 10.1 per cent for the 21-35-year-old age group compared to 19.0 per cent for the 51-65-year-old age group. The corresponding reductions are 10.6 and 22.3 per cent for single-plan households.

Under community rating, individuals will pay the same price for insurance regardless of age or health status, but the older age group will still receive larger insurance payouts.

Under age-rated premiums younger cohorts will pay lower premiums than older cohorts regardless of whether there is reinsurance. However, reinsurance will reduce the relative ratio of premiums paid by older cohorts to the premiums paid by younger cohorts. This reduction in relative premiums may make age-rated premiums more palatable for older cohorts.

Tabulations presented in Tables 5 and 6 examine whether reinsurance creates an incentive for insurance firms to insure all individuals regardless of their health status. The impact of reinsurance on health expenditures is compared to the impact of excluding households with at least one member with one of three diseases - diabetes, 
Table 4 The impact of reinsurance by plan type and age group

\begin{tabular}{lcccc}
\hline Plan type & Age & $\begin{array}{c}\% \text { change between reinsurance } \\
\text { over US\$50,000 to no reinsurance }\end{array}$ & $\begin{array}{c}\text { Relative price } \\
\text { no reinsurance }\end{array}$ & $\begin{array}{c}\text { Relative price } \\
\text { with reinsurance }\end{array}$ \\
\hline Family & $21-35$ & 10.1 & 0.51 & 0.54 \\
Family & $36-50$ & 11.7 & 0.95 & 0.99 \\
Family & $51-65$ & 19.0 & 1.48 & 1.41 \\
Family & All families & 15.0 & 1.00 & 1.00 \\
Single & $21-35$ & 10.6 & 0.45 & 0.48 \\
Single & $36-50$ & 16.1 & 1.08 & 1.10 \\
Single & $51-65$ & 22.3 & 2.24 & 2.16 \\
Single & All singles & 17.7 & 1.00 & 1.00 \\
\hline
\end{tabular}

Source: Tabulations from MEPS 1999 to 2006 based on insurance expenditure algorithm.

Table 5 Estimated health insurance expenditures - impact of exclusions and reinsurance

\begin{tabular}{lcccccr}
\hline $\begin{array}{l}\text { Plan } \\
\text { type }\end{array}$ & $\begin{array}{c}\text { Age of } \\
\text { household } \\
\text { head }\end{array}$ & $\begin{array}{c}\text { No reinsurance } \\
\text { everyone } \\
\text { included US } \$\end{array}$ & $\begin{array}{c}\text { No reinsurance } \\
\text { disease } \\
\text { excluded US } \$\end{array}$ & $\begin{array}{c}\text { Reinsurance } \\
\text { everyone } \\
\text { included } \text { US } \$\end{array}$ & $\begin{array}{c}\text { Reinsurance } \\
\text { disease } \\
\text { excluded US } \$\end{array}$ & $\begin{array}{c}\% \\
\text { excluded }\end{array}$ \\
\hline Family & $21-35$ & US $\$ 5,427$ & US $\$ 5,237$ & US $\$ 4,863$ & US $\$ 4,736$ & 2.1 \\
Family & $36-50$ & US $\$ 9,846$ & US $\$ 9,192$ & US $\$ 8,671$ & US $\$ 8,153$ & 7.4 \\
Family & $51-65$ & US $\$ 15,651$ & US $\$ 12,575$ & US $\$ 12,615$ & US $\$ 10,439$ & 22.7 \\
Family & $21-65$ & US $\$ 10,527$ & US $\$ 8,951$ & US $\$ 8,910$ & US $\$ 7,763$ & 11.0 \\
Single & $21-35$ & US $\$ 1,071$ & US $\$ 1,052$ & US $\$ 1,046$ & US $\$ 1,027$ & 0.9 \\
Single & $36-50$ & US $\$ 2,773$ & US $\$ 2,534$ & US $\$ 2,417$ & US $\$ 2,199$ & 5.4 \\
Single & $51-65$ & US $\$ 5,846$ & US $\$ 4,719$ & US $\$ 4,825$ & US $\$ 3,914$ & 15.0 \\
Single & $21-65$ & US $\$ 2,636$ & US $\$ 2,207$ & US $\$ 2,290$ & US $\$ 1,938$ & 5.4 \\
\hline
\end{tabular}

Source: Tabulations from MEPS 1999 to 2006 based on insurance expenditure algorithm.

Table 6 Impact of exclusions on health expenditures

\begin{tabular}{|c|c|c|c|c|c|}
\hline \multirow[t]{2}{*}{ Plan type } & \multirow{2}{*}{$\begin{array}{c}\text { Age of } \\
\text { household head }\end{array}$} & \multicolumn{2}{|c|}{ No reinsurance } & \multicolumn{2}{|c|}{ Reinsurance } \\
\hline & & US\$ Gain & $\begin{array}{c}\text { US\$ Gain per } \\
\text { household excluded }\end{array}$ & US\$ Gain & $\begin{array}{c}\text { US\$ Gain per } \\
\text { household excluded }\end{array}$ \\
\hline Family & $21-35$ & US \$189 & US $\$ 14,403$ & US \$127 & US $\$ 9,684$ \\
\hline Family & $36-50$ & US \$654 & US \$18,014 & US \$518 & US \$14,252 \\
\hline Family & $51-65$ & US $\$ 3,076$ & US \$26, 140 & US \$2,177 & US \$18,499 \\
\hline Family & $21-65$ & US $\$ 1,576$ & US $\$ 23,353$ & US $\$ 1,148$ & US $\$ 17,002$ \\
\hline Single & $21-35$ & US \$19 & US $\$ 3,109$ & US \$19 & US $\$ 3,145$ \\
\hline Single & $36-50$ & US $\$ 240$ & US \$6,974 & US \$218 & US $\$ 6,341$ \\
\hline Single & $51-65$ & US $\$ 1,126$ & US $\$ 12,247$ & US \$911 & US $\$ 9,910$ \\
\hline Single & $21-65$ & US $\$ 429$ & US $\$ 10,162$ & US \$353 & US $\$ 8,360$ \\
\hline
\end{tabular}

Source: Tabulations from MEPS 1999 to 2006 based on insurance expenditure algorithm.

coronary heart disease and emphysema. This type of insurance selection scheme is actually very primitive because as noted by Cutler and Zeckhauser ${ }^{12}$ insurance companies can tailor their insurance coverage to discourage enrolment by high-risk 
individuals. In fact, insurance firms have detailed information on patient characteristics and usage patterns that they can use in designing health plans and in making coverage decisions.

Table 5 presents average insurance expenditures with and without reinsurance for the entire sample and for individuals who are excluded because they have a disease. The last column of Table 5 contains statistics on the number of individuals who are excluded because they have one of the three diseases. For family plans the percent excluded ranges from 2.1 per cent for the 21-35-year-old age group to 22.7 per cent for the 51-65-year-old age group.

The data in Table 6 illustrates potential gains from excluding individuals with one of the three diseases. This data reveals that even when reinsurance exists a policy of excluding sick individuals from obtaining insurance coverage will be effective at reducing insurance expenditures. The average dollar reduction in health insurance expenditures over all households from this primitive exclusion strategy is US $\$ 1,148$ for family plans and US $\$ 353$ for single plans. The gain from households excluded is US $\$ 17,002$ for family plans and US $\$ 8,360$ for single plans. The gain from exclusion strategies on a per-household basis tend to rise with age, but excluding sicker young households will also reduce insurance expenditures.

\section{Conclusions and policy implications}

A subsidised reinsurance programme for health insurance markets could lower costs and insurance plan risk, which should expand coverage. However, even if reinsurance is adopted, younger healthier individuals will still subsidise insurance premiums for older sicker individuals in community-rating States. Even with reinsurance, affordability may not materially improve for younger cohorts and insurance firms will have an incentive to deny coverage to sicker predominantly older individuals.

One advantage of reinsurance programmes may be to create political support for health care regulatory schemes, which are currently opposed by the insurance industry. The current health care reform debate in the United States centres on the creation of a health care regulatory structure, which facilitates greater access to affordable coverage for all cohorts regardless of age or health status. Reinsurance by shifting risks away from specific insurance firms could reduce insurance firm opposition to the elimination of current industry measures used to weed out bad risks.

Publicly funded reinsurance programmes also provide a subsidy, which is shared between the insurance industry and its consumers. Federal tax or financial subsidies are created to achieve social objectives. One way to facilitate the adoption of State insurance laws providing affordable access for older or sick individuals is to restrict the availability of publicly funded reinsurance to States that adopt health insurance regulatory laws that are consistent with this objective. Butler ${ }^{16}$ elaborates on the

\footnotetext{
${ }^{16}$ Butler (2007).
} 
connection between risk-adjustment and incentives for the adoption of age-rated premiums rules. $^{17}$

Health insurance subsidies are provided through the tax code under the current health care system in the United States. If U.S. policy-makers desire to maintain health insurance subsidies at their current level, the creation of a subsidised reinsurance programme could justify the reduction of current tax-based subsidies.

One of the most difficult aspects of regulatory reform is the creation of a system that is fair to all age cohorts. Under community rating rules, younger cohorts unambiguously subsidise premiums for older cohorts. This inter-generational subsidy is reduced, or even eliminated, through the adoption of age-rated regulations. It is critically important to persuade younger individuals to purchase health insurance because this relatively health cash-poor group may not fully see the value of health insurance. However, older cohorts may not be able to afford insurance when insurance regulations favour the younger cohort. The choice of an age-rated formula is zero-sum game because alterations favouring the young adversely impact the old and vice versa. However, the reduction in insurance company expenditures paid to older cohorts because of reinsurance will reduce the amount insurance companies desire to charge older cohorts. This change in industry preference could in turn impact the age-rated ratio selected by State regulators.

A health insurance reinsurance programme will reduce but not eliminate the incentive for health insurance companies to "cherry pick" healthier young health insurance applicants and reject older or sicker applicants. However, reinsurance by reducing risk could make insurance reform economically viable and politically palatable.

\section{References}

Berk, M.L. and Monheit, A.C. (1992) 'The concentration of health expenditures: An update', Health Affairs, 11(Winter): 145-149.

Berk, M.L. and Monheit, A.C. (2001) 'The concentration of health care expenditures, revisited', Health Affairs, 20(March/April): 9-18.

Berk, M.L., Monheit, A.C. and Hagan, M.M. (1988) 'How the U.S. spent its health care dollar: 1929-1980', Health Affairs, 8(Fall): 46-80.

Bernstein, D. (2008) 'Intergenerational transfers and insurance policy design', North American Actuarial Journal 12(3): 290-298.

Blumberg, L.J. and Holahan, J. (2004) 'Government as reinsurer: Potential impacts of public and private spending', Inquiry 41(2): 130-143.

Butler, S. (2007) Evolving Beyond Traditional Employer-Sponsored Health Insurance, Discussion Paper, Washington, DC: The Hamilton Project, The Brookings Institution.

${ }^{17}$ Butler (2007) identifies this relationship on page 23 of his report. He writes: "To arrange stable and affordable coverage, states also need to experiment with ways to adjust for selection effects among plans within the pool. Age-related premium bands, for example, would make coverage more affordable for younger, healthier individuals, inducing those who are better risks to participate in the pool. States might also apply reinsurance or insurer 'risk-transfer' pool requirements to all coverage sold within a state, whether inside or outside of the exchange". 
Center for Affordable Health Insurance (2006) 'State Health Insurance 2006: A 50-State Comparison of the Nation's Health Insurance Market', from www.cahi.org/cahi_contents/resources/pdf/StateIndex .$p d f$.

Clemens-Cope, L. and Bowen, G. (2006) 'Changes in Employer-Sponsored Health Insurance Sponsorship Eligibility, and Participation: 2001 to 2005', Issue Paper, Washington DC, Kaiser Commission on Medicaid and the Uninsured.

Collins, S.R., Schoen, C., Kriss, J.L., Doty, M.M. and Mahato, B. (2006) 'Rite of Passage? Why Young Adults Become Uninsured and How New Policies Can Help', Issue brief, The Commonwealth Fund, May 2006.

Cutler, D. and Zeckhauser, R. (2000) 'The anatomy of health insurance', in A.J. Cuyler and J.P. Newhouse (eds.) Handbook of Health Economics, Amsterdam: Elsevier Science, pp. 563-644.

Jacobson, G., Schwartz, K. and Neuman, T. (2009) 'Health Insurance Coverage for Older Adults: Implications of a Medicare Buy-in', Kaiser Family Foundation, Issue Brief, 05-14-2009.

Kofman, M. and Politz, K. (2006) Health Insurance Regulation by States and the Federal Government: A Review of Current Approaches and Proposals for Change?, Health Policy Institute, Georgetown University. From http://www.allhealth.org/briefingmaterials/HealthInsuranceReportKofmanandPollitz-95 .$p d f$.

Newhouse, J.P. (1986) 'Cream skimming asymmetric information, and a competitive insurance market', Journal of Health Economics 3(1): 97-100.

Selden, T.M., Levit, K.R., Cohen, J.W., Zuvekas, S.H., Moeller, J.F., McKusick, D. and Arnett, R.H. (2001) 'Reconciling medical expenditure estimates from the MEPS and NHA', Health Care Financing Review 23(1): 161-178.

Swartz, K. (2003) 'Reinsuring risk to increase access to health insurance', AEA Papers and Proceedings, May 2003. 